\title{
INTERACTION BETWEEN CLOVER ROOT WEEVIL AND CLOVER ROOT TYPE
}

\author{
D.A. CARE, J.R. CRUSH, S. HARDWICK, \\ S.N. NICHOLS and L. OUYANG \\ AgResearch, Ruakura Research Centre, Private Bag 3123, Hamilton
}

\begin{abstract}
A slant board experiment investigated the effect of four white clover (Trifolium repens $\mathrm{L}$.) root types on tolerance of root feeding by larvae of clover root weevil (Sitona lepidus Gyllenhål). Root damage was determined by image analysis and larval weight gains were measured. Differences in root type did not have a major impact on initial damage by clover root weevil. However different root types were affected differently by the clover root weevil. A clover genotype with long fine roots had more functional root length after larval feeding than genotypes with different root types.
\end{abstract}

Keywords: clover root weevil, Sitona lepidus, white clover, root morphology.

\section{INTRODUCTION}

Clover root weevil (CRW) (Sitona lepidus Gyllenhål(Coleoptera: Curculionidae)) was first identified in New Zealand in 1996 (Barratt et al. 1996). This insect is known to be present from south of Whangarei to just north of Lake Taupo in the North Island. The widespread European distribution of CRW suggests that it will eventually colonise the whole country (Willoughby et al. 1999). Adult CRW feed on the foliage of host species (Murray and Clements 1992), while the soil-dwelling larvae feed on roots and nodules (Byers and Kendall 1982). This pest presents a threat to the profitability of pastoral farming in New Zealand as farmers rely on white clover to fix nitrogen and provide highly nutritious feed (Caradus et al. 1995; Ulyatt et al. 1977).

Root herbivory reduces the host's absorptive surface and provides entry points for disease. Compensatory root growth in response to Sitona feeding may impair shoot growth (Quinn and Hall 1992). The energy invested to repair root damage by Sitona on Medicago sativa can deplete carbohydrate reserves in the plant (Goldson et al. 1988). Different commercial clover species have shown only limited variation in tolerance to the CRW adults (Murray and Willoughby 1998). There is substantially wider variation in root types in current clover breeding programmes than exists in commercial cultivars. This variation includes differences in root tissue density and extremes in root morphology. A plant with a finely divided, intensive root system may persist because the larvae cannot destroy enough roots to kill the plant. A large taproot may resist grazing near the root surface and maintain root function by avoiding herbivory at depth. Roots of different biochemistry may differ in their palatability to the CRW larvae.

This paper describes an experiment that investigated the effect of CRW larval feeding on four white clover genotypes with contrasting root characteristics.

\section{Plant preparation}

\section{MATERIALS AND METHODS}

Two clover genotypes with contrasting root morphology (STR- short, thick roots and LFR- long, fine roots) and two with different soluble carbohydrate accumulation patterns (HCR-high carbohydrate roots and LCR-low carbohydrate roots) were used 
for the experiment. Thirty stolon tips (about 40-50 $\mathrm{mm}$ long) of each genotype were grown in hydroponic culture (Care 1995). After eleven days in culture, when the new roots were 100-120 mm long, the twenty largest plants of each genotype were transferred to slant boards as described below.

\section{Slant boards}

The slant boards used were similar to those described in Hardwick and Prestidge (1996). However, in this experiment the capillary matting had been soaked in a nutrient solution (minus nitrogen). The same solution was supplied to the plants throughout the experiment. Each slant board contained a single white clover genotype. Before the roots of the clover plant were enclosed $2 \mathrm{ml}$ of a Rhizobium suspension was added to each slant board. The experiment was done in a controlled environment room at $18^{\circ} \mathrm{C}$ under a photoperiod of 16:8 h light:dark.

\section{Larval treatment}

CRW larvae were collected from the Ruakura Research Farm $24 \mathrm{~h}$ before the experiment. The late instar larvae were placed singly into compartments in an ice cube tray, covered with moist paper towels and stored at $5^{\circ} \mathrm{C}$ until approximately $2 \mathrm{~h}$ before introduction into the slant boards. The larvae were sorted into groups of five, weighed and then placed into the slant boards.

\section{Experimental design}

Twenty replicates of the four plant genotypes were arranged in a randomised block design. After six days the plants were carefully removed from the slant board. The roots were laid out on a perspex sheet and scanned using the WinRhizo ' image analysis programme (Harvest 1). After scanning, the clovers were put back onto the slant boards. A small amount of water was added to the clovers and the boards were put back in the controlled environment room. Five CRW larvae were weighed and added to half the replicates of each plant treatment (10 replicates/treatment).

Five days after the larvae were introduced they were removed from the slant boards, counted and weighed. The white clover plants were then removed from the slant boards, total fresh plant weight recorded and the shoots separated from the roots. Attached roots and severed roots were laid out and scanned separately (Harvest 2). Fresh and dried weights of plant shoots, attached roots, severed roots and larvae were recorded.

Root morphology measurements of attached and severed roots, root and shoot dry weights and mean weight gain/weevil were analysed using ANOVA in MINITAB.

\section{RESULTS}

There were no significant differences in root length, area and volume between plants of the same genotypes assigned to the plus and minus weevil treatments prior to the addition of larvae (Table 1). Five days after addition of larvae, all plant genotypes without larvae had significantly $(\mathrm{P}<0.001)$ greater root lengths, areas and volumes. Average root diameters were not significantly different between treatments for each plant genotype. Shoot dry weights did not differ between larval treatments. Only results for root length are presented because the trends for the other root morphology measurements (root volume and surface area) followed the same pattern.

There was a significant treatment (presence or absence of larvae) by clover genotype interaction $(\mathrm{P}<0.01)$ for root length. Thus, in the minus larvae treatments, the root length of all four genotypes increased significantly over the five day period, however the roots all grew at different rates for the four genotypes. In the plus larvae treatment the LFR genotype grew $61 \mathrm{~cm}$ of new attached root compared to $28-43 \mathrm{~cm}$ for the other clovers (Table 1).

The length of roots severed by larval grazing was not significantly different between genotypes. Between 39-60\% of the total root length was removed.

There were significant differences between the LFR and STR genotypes for the root morphological measurements. The HCR and LCR genotypes were very similar to the STR genotypes in root morphology measurements. Carbohydrate analyses were not done in this experiment. 
TABLE 1: Root length $(\mathrm{cm})$ attached to the shoots of the four genotypes, in minus larvae and plus larvae treatments at Harvest 1 (6 days after the plants were placed on the slant boards) and Harvest 2 (5 days later, after the addition of clover root weevil larvae to the plus larvae treatments). LSDs are for comparison of genotypes and plus and minus larvae treatements, within Harvest 1 or Harvest 2. Genotypes are LFR-long, fine roots; STR-short, thick roots; HCR-high carbohydrate roots; LCR low carbohydrate roots.

\begin{tabular}{|c|c|c|c|c|}
\hline \multirow[t]{2}{*}{ Genotype } & \multicolumn{2}{|c|}{ Harvest 1} & \multicolumn{2}{|c|}{ Harvest 2} \\
\hline & minus larvae & plus larvae & minus larvae & plus larvae \\
\hline LFR & 341 & 305 & 688 & 366 \\
\hline STR & 145 & 153 & 305 & 181 \\
\hline HCR & 163 & 150 & 398 & 185 \\
\hline LCR & 136 & 137 & 323 & 180 \\
\hline $\operatorname{LSD}(\mathrm{P}<0.05)$ & \multicolumn{2}{|c|}{60} & \multicolumn{2}{|c|}{117} \\
\hline
\end{tabular}

The average root diameters were $0.05 \mathrm{~cm}$ for LFR and $0.06 \mathrm{~cm}$ for the other genotypes at Harvest $1(\mathrm{P}<0.05)$ and diameter decreased to $0.04 \mathrm{~cm}$ for all genotypes at Harvest 2, whether larvae were present or not. This similarity in root diameters suggests that the inherent growth pattern of the plants' roots was not affected by larval feeding.

Following larval feeding the root lengths per unit root weight (specific root length) for all genotypes decreased and root density increased (Table 2). There were no significant differences in mean weevil weight change over the experimental period (Table 2).

TABLE 2: Specific root length (cm of root length/mg of root dry weight) and tissue density (mg of root dry weight $/ \mathrm{cm}^{3}$ root volume) of the roots attached to the root system, in the presence and absence of larvae. The mean larval weight change over five days is also shown. Genotypes are LFR-long, fine roots; STR-short, thick roots; HCRhigh carbohydrate roots; LCR low carbohydrate roots.

\begin{tabular}{|c|c|c|c|c|c|}
\hline \multirow{3}{*}{ Genotype } & \multicolumn{2}{|c|}{ Specific root length } & \multicolumn{2}{|c|}{ Tissue density } & \multirow{3}{*}{$\begin{array}{c}\text { Larval weight } \\
\text { change } \\
(\mathrm{mg})\end{array}$} \\
\hline & minus & plus & minus & plus & \\
\hline & larvae & larvae & larvae & larvae & \\
\hline LFR & 15.6 & 11.1 & 22.2 & 61.7 & 0.4382 \\
\hline STR & 11.2 & 7.7 & 31.91 & 78.46 & 0.4344 \\
\hline HCR & 13.2 & 7.5 & 22.47 & 77.19 & 0.9890 \\
\hline LCR & 13.9 & 8.8 & 28.97 & 75.25 & 0.3670 \\
\hline LSD $(\mathrm{P}<0.05)$ & \multicolumn{2}{|c|}{2.6} & \multicolumn{2}{|c|}{20.6} & 2.5 \\
\hline
\end{tabular}

\section{DISCUSSION}

For all four genotypes the effect of CRW larval grazing can be seen in the differences in root length between harvests and between treatments at Harvest 2. On slant boards roots are confined to one plane, and it is possible damage may be more severe than in the field where root distribution is less restricted. However, the technique has proved useful to study the interaction between CRW larvae and clover genotypes. During the experiment some larvae moved up the root system and tunnelled into the stolons. This behaviour has been observed in the field and suggests that the carbohydrate reserves in clover stolons (Lawson et al. 1998) may be attractive to older larvae. 
The long fine root genotype maintained a significantly larger root system in the presence of larvae than did the other three types. This study and other current research (D. Care, unpubl. data) have shown that this genotype generally has a longer total root system, which is more than twice the length of the other three genotypes. At any level of larval density, a large finely divided root system should suffer less severe damage than a system with fewer and coarser roots. This tolerance of root feeding by clovers with extensive fine roots needs testing in the field. Root systems that have the ability to persist and recover faster from herbivory will have major benefits in the pastoral system response to weevil infestation.

The root morphology measurements suggest that the three-fold increase in root density after root feeding was not caused by changes in root architecture. We are not aware of any other reports of an increase in root tissue density in response to herbivory. This could be a plant defence mechanism against herbivory, with additional structural tissue being laid down. Such a response could explain some of the energy costs of Sitona damage to lucerne noted by Goldson et al. (1988). Other genotypes that we have selected for variation in root tissue density should be tested for their respnse to root herbivory.

The lack of any differences between genotypes in the amount of root severed by the larvae suggests that no lines were preferentially eaten or avoided. Although the amount of root consumed by the larvae is unknown, larval weights suggest similar intake in at least three genotypes. For plant survival it is the amount of root left attached to the plant that is important.

The roots of all four lines continued to grow under larval grazing. For LFR this continued root growth probably relates to root morphology; for HCR this may relate to the higher soluble carbohydrate status of the roots of this genotype. At the end of the experiment, larvae feeding on the high carbohydrate root genotype were 2-3 times heavier than larvae feeding on the other genotypes. The difference did not achieve statistical significance because of the small number of larvae used and variations in larval age. These data do suggest that the carbohydrate status of the root has an important influence on larval growth rate. The experiment was not capable of demonstrating that larvae on the HCR roots ate less, because there was no comparable low carbohydrate root controls with identical root morphology. Goldson et al. (1988) showed that the energy invested in repair of lucerne roots damaged by Sitona discoides depleted carbohydrate reserves in the plant. This carbohydrate depletion may be less severe in the HCR genotype. The interaction between CRW larvae and the high carbohydrate status clover root genotype needs further investigation to see if this root characteristic should be selected for, or against, in the search for CRW tolerant clover germplasm.

\section{ACKNOWLEDGMENTS}

This work was funded by AgResearch from the Public Good Science Fund, Nonspecific output funding.

\section{REFERENCES}

Barratt, B.I.P., Evans, A.A. and Addison, P.J., 1996. Sitona lepidus Gyllenhal (Coleoptera:Curculionidae) a potential clover pest new to New Zealand. N.Z. Entomologist 19: 23-30.

Byers, R.A. and Kendall, W.A., 1982. Effects of plant genotypes and root nodulation on growth and survival of Sitona spp. Larvae. Environ. Entomol. 11: 440-443.

Caradus, J.R., Woodfield, D.R. and Stewart, A.D., 1995. Overview and vision for white clover. Agron. Soc. N.Z. Special Publication 11: 1-6.

Care D.A., 1995. The effect of aluminium concentration on root hairs in white clover (Trifolium repens L.). Plant and Soil 171: 159-162.

Goldson, S.L., Jamieson, P.D. and Bourdôt, G.W., 1988. The response of field grown lucerne to a manipulated range of insect-induced stresses. Ann. Appl. Biol. 113: 189-196. 
Hardwick, S. and Prestidge, R.A., 1996. Effects of whitefringed weevil larval feeding on ryegrass and white clover in the laboratory. Proc. 49 th N.Z. Plant Prot. Conf.: 244-248.

Lawson, A.R., Kelly K.B. and Sale P.W.G., 1998. Defoliation frequency and genotype effects on stolon and root reserves in white clover.Aust. J. Agric. Res. 6: 983-988.

Murray, P.J. and Clements, R.O., 1992. A technique for assessing damage to roots of white clover caused by root feeding insects. Ann. Appl. Biol. 121: 715-719.

Murray, P.J. and Willoughby, B., 1998. Feeding preferences of Sitona lepidus (Clover root weevil) on Trifolium spp. in New Zealand. Tests of Agrochemicals and Cultivars 19:58-59.

Quinn, M.A. and Hall, M.H., 1992. Compensatory response of a legume root-nodule system to system to nodule herbivory by Sitona hispidulus. Entomol. Exp. Appl. 64: $167-176$.

Ulyatt, J.J., Lancashire, J.A. and Jones, W.T., 1977. The nutritive value of legumes. Proc. N.Z. Grasslands Assoc. 38: 107-118.

Willoughby, B., Addison, P., Hardwick, S., Gerard, P. and Goldson S., 1999. Clover root weevil (Sitona lepidus) - The New Zealand experience; strategies adopted to combat this threat. Proc. 7th Australasian Conf. on Grassland Invert. Ecol.: 3543. 